\title{
Coping of staff nurses in losing patients: assessment utilizing the developed coping interventions tool for nurses (CIT-N)
}

\begin{abstract}
Nurses encounter death more than most. Death is inevitable and also a reality of life that everyone has to deal with. This descriptive research aimed to assess the coping of staff nurses utilizing the developed Coping Interventional Tool for Nurses (CIT-N). 1 A total of 51 staff nurses from two-respondent hospitals were selected based on the set criteria. Later, the study revealed that majority of the staff nurses, in both respondent hospitals, were observed to be high in their coping after losing patients. In addition, there is no significant difference between their assessed coping. For Hospital A, delivering their nursing care to the dying patients with utmost professionalism and believing that acceptance plays a vital role in the process commonly contributed in their coping after losing patients. For Hospital B, it is still grateful that their rendered nursing services adds to the quality of life towards the peaceful death of the dying patients.
\end{abstract}

Volume 3 Issue 2 - 2019

\section{John Christian VVillanueva}

Department of Education, Dr. Gloria D. Lacson Foundation Colleges Inc, Philippines

Correspondence: John Christian V Villanueva, Department of Education, Dr. Gloria D. Lacson Foundation Colleges Inc, Philippines, Tel +6391682604I3,

Email villanuevajohnchristian@ymail.com

Received: February 27, 2019 | Published: April 08, 2019

\section{Introduction}

Nurses encounter death more than most. Though doctors and other hospital personnel are also exposed to death and suffering, but nurses may be more susceptible to the lasting emotional impact. Nurses spend the most time with patients individually and have a hand in every level of their care.

Death is inevitable and also a reality of life that everyone has to deal with. Nurses work on the front lines of patient care, and kindness and compassion are crucial attributes that all nursing professionals should exhibit. Consequently, it is common for nursing staff to form emotional attachments with patients and subsequently become affected by feelings of grief after a patient die - after all nurses are humans.

They come across death and part of their profession is learning how to cope with loss. Nurses are sometimes trained how to help families deal with their loved one's death, seldom are nurses trained on how they too can deal with the loss of a patient. It can be a very disturbing and distressing time for a nurse when this occurs, especially if the nurse was attached to the patient.

Death and dying can dramatically impact the caregiver. People experiencing loss often search for the meaning of the event, and it is generally accepted that finding meaning is needed in order for recovery to occur.

Service to individuals at the end of life and their families is an experience rich with meaning. Opportunity for life review, recovery and reminiscing legacy are some important tasks that can be accomplished during life's end. It is a time of potentially reflective emotions and spiritual connections, letting go of the physical self and embracing the intangible reality. Nurses who had a more positive attitude towards death were more likely to have a positive attitude towards providing end of life care for patients. To be involved professionally at this crucial time is deeply worthwhile and yet challenging.
The purpose of this study is to assess the coping of staff nurses in losing patients utilizing the developed Coping Interventional Tool for Nurses (CIT-N). ${ }^{1}$

\section{Statement of the problem}

The researcher assessed the coping of staff nurses in losing patients. Specifically, the research designed to come up with valuable data and information to the following:

a. How may the profile variables of staff nurses be described in terms of:

\section{Age;}

Gender; and

length of experience?

b. How may the coping of staff nurses be assessed utilizing Coping Interventional Tool for Nurses (CIT-N) ${ }^{1}$

c. Is there a significant difference between the assessed coping of staff nurses in losing patients from two-respondent hospitals?

\section{Method}

This study addressed to assess the coping of staff nurses in losing patients. This study used descriptive method of research, though comparative in nature, and utilizing quantitative approach.

As term implies, it proceeds to describe certain phenomena. It is described to be "fact-finding" or "information gathering" with analytical interpretations. It is concerned with conditions or relationships that exist; practices that prevail; beliefs and processes that are going on; effects that are being felt or trends that are developing. The descriptive method is something more and beyond, than just data-gathering. The true meaning of the data collected should be reported from the point of view of the objectives and the basic assumptions of the study. 
The study was conducted in two private hospitals in the municipality of San Leonardo, Province of Nueva Ecija. Purposive sampling was used in the study to select the staff nurses to elicit data that should be substantial to the research study and to answer the research questions comprehensively. Respondents (Hospital A-21 and Hospital B-30) were selected based on the following criteria in this study: (a) they are assigned in Emergency Department, Intensive Care Unit, Neonatal Intensive Care Unit and/or General Ward; and (b) they have experience/s in dealing with dying patients.

The questionnaire was the primary instrument of the study. It was adopted from Villanueva's research (2017) entitled "Biag Ikararuwa: Coping Experiences of Filipino Nurses." It contains of two parts. The first part aims to gather information on the profile variables of the respondents - their age, gender and length of experience. The second part consists of 10 close-ended questions that aim to elicit their response as to coping practiced by the staff nurses in losing patients. Before these items is a direction on how they will complete the questionnaire, including a guide to what are the meanings of the rating scale.

To arrive at a verbal description of each of the item-statements, the following arbitrary numerical guide was used:

\begin{tabular}{lll}
\hline Arbitrary value & Range & Verbal interpretation \\
\hline 4 & $3.26-4.00$ & Strongly agree \\
3 & $2.51-3.25$ & Agree \\
2 & $1.76-2.50$ & Disagree \\
1 & $1.00-1.75$ & Strongly disagree \\
\hline
\end{tabular}

\section{Results and discussion}

Table 1 presents the distribution of the respondents according to age. For Hospital A, 19 or $90 \%$ belonged to the age bracket of $21-30$ years old while two or $10 \%$ belonged to the age bracket of $31-40$ years old.

Table I Age distribution of the respondents

\begin{tabular}{lllll}
\hline \multirow{2}{*}{ Age } & Hospital A & \multicolumn{3}{c}{ Hospital B } \\
\cline { 2 - 4 } & F & P & F & P \\
\hline Below 20 years old & 0 & 0 & 0 & 0 \\
21-30 years old & 19 & $90 \%$ & 18 & $60 \%$ \\
$31-40$ years old & 2 & $10 \%$ & 12 & $40 \%$ \\
4I-50 years old & 0 & 0 & 0 & 0 \\
More than 5I years old & 0 & 0 & 0 & 0 \\
Total & 21 & $100 \%$ & 30 & $100 \%$ \\
\hline
\end{tabular}

For Hospital B, 18 or $60 \%$ belonged to the age bracket of $21-30$ years old while 12 or $40 \%$ belonged to the age bracket of $31-40$ years old.

Most of the staff nurses belonged to the age bracket of 21-30 years old. According to Finkelman \& Kenner $^{2}$ specialties, such as intensive care units and emergency departments, usually attract younger nurses because of the fast-paced nature of the work. They added that due to nursing shortage, hospitals have difficulty attracting experienced nurses to fill these positions with this type of settings.

The length of experience of the respondents is presented in Table 2. For Hospital A, 14 or $67 \%$ respondents have 1-3 years in length of experience, 4 or 19\% have 4-6 years in length of experience, while 3 or $14 \%$ have more than 7 -year experience.
Table 2 Length of experience of the respondents

\begin{tabular}{lllll}
\hline \multirow{2}{*}{ Length of experience } & \multicolumn{2}{l}{ Hospital A } & \multicolumn{2}{l}{ Hospital B } \\
\cline { 2 - 5 } & F & P & F & P \\
\hline I-3 years & 14 & $67 \%$ & 10 & $33 \%$ \\
4-6 years & 4 & $19 \%$ & 15 & $50 \%$ \\
More than 7 years & 3 & $14 \%$ & 5 & $17 \%$ \\
Total & 21 & $100 \%$ & 30 & $100 \%$ \\
\hline
\end{tabular}

For Hospital B, 10 or 33\% respondents have 1-3 years in length of experience, 15 or $50 \%$ have $4-6$ years in length of experience, and 5 or $17 \%$ have more than 7 -year experience. The data show that most of the respondents belonged to 1-3 years in length of experience.

Table 3 presents the gender distribution of the respondents. For Hospital A, $43 \%$ respondents are males and 11 or $52 \%$ who are females.

Table 3 Gender distribution of the respondents

\begin{tabular}{lllll}
\hline \multirow{2}{*}{ Gender } & \multicolumn{2}{l}{ Hospital A } & \multicolumn{2}{l}{ Hospital B } \\
\cline { 2 - 5 } & F & P & F & P \\
\hline Male & 9 & $43 \%$ & 6 & $20 \%$ \\
Female & II & $52 \%$ & 24 & $80 \%$ \\
Total & 21 & $100 \%$ & 30 & $100 \%$ \\
\hline
\end{tabular}

For Hospital B, 6 or $20 \%$ respondents are males and 24 or $80 \%$ are females. Data show that majority of the respondents are females. Based on Atkins ${ }^{3}$ there are social and historical factors that have contributed to the female domination of nursing. For example, Florence Nightingale, known as the founder of modern nursing practice, promoted the image of nurses as nurturing, subordinate and female. And for a number of reasons this image took hold in society. One of the factors the solidified nursing as a female-dominated profession is that for most of the 1900 s, there were few professions open for women besides elementary school education, social work and nursing; and women are more likely to enter these fields for the same reasons.

In the Table 4, the following limits and degrees were employed: 12-18 (very low); 19-25 (low); 26-32 (moderate); 33-40 (high); and 41-48 (very high). Majority of the staff nurses, in Hospital A, 12 or 57.14 percent, and in Hospital B, 17 or 56.67 percent, were observed to be high in their coping in losing patients. Result could imply that they cope effectively as expected in their field of profession and concurrently being trained as they experienced such.

Table 4 Degree and frequency distribution relative to the assessed coping of the staff nurses in losing patients

\begin{tabular}{llllll}
\hline Limits & Degrees & \multicolumn{2}{c}{ Hospital A } & \multicolumn{2}{c}{ Hospital B } \\
\cline { 3 - 6 } & & f & $\%$ & f & $\%$ \\
\hline $12-18$ & Very low & 0 & 0 & 0 & 0 \\
$19-25$ & Low & 0 & 0 & 0 & 0 \\
$26-32$ & Moderate & 0 & 0 & 0 & 0 \\
$33-40$ & High & 12 & 57.14 & 17 & 56.67 \\
$41-48$ & Very high & 9 & 42.86 & 13 & 43.33 \\
Total & & 21 & 100.00 & 30 & 100.00 \\
\hline
\end{tabular}

Table 5 presents the assessed coping of staff nurses in losing patients utilizing the developed Coping Interventional Tool for Nurses 
(CIT-N). ${ }^{1}$ For Hospital A, item no. 2 which states that, "I deliver nursing care to the dying patients with certain degree of altruism, special attainment, self-sacrifice, right attitude and understanding of responsibilities and concerns" and item no. 10 which states that, "I believe that acceptance plays an important factor in order to cope with death/ losing patients" got the highest weighted mean of 3.70 with verbal interpretation of strongly agree. Followed by item no. 6 which states that, "I utilized my knowledge in death experiences to enhance my nursing care" with a weighted mean of 3.60 with verbal interpretation of strongly agree. While item no. 1 which states that, "I render end-of-life care which involves supporting the general wellbeing of patients" got the lowest weighted mean of 3.00 with verbal interpretation of agree.

Table 5 Assessed coping of the staff nurses in losing patients utilizing the developed coping interventional tool for nurses (CIT-N)'

\begin{tabular}{|c|c|c|c|c|}
\hline \multirow[t]{2}{*}{ Items } & \multicolumn{2}{|c|}{ Hospital A } & \multicolumn{2}{|c|}{ Hospital B } \\
\hline & WM & D & WM & D \\
\hline I. I render end-of-life care which involves supporting the general well-being of patients. & 3.00 & Agree & 3.47 & Strongly agree \\
\hline $\begin{array}{l}\text { 2. I deliver nursing care to the dying patients with certain degree of altruism, special } \\
\text { attainment, self-sacrifice, right attitude and understanding of responsibilities and concerns. }\end{array}$ & 3.70 & Strongly agree & 3.33 & Strongly agree \\
\hline $\begin{array}{l}\text { 3. I am still grateful for the services rendered towards peaceful death of patient besides my } \\
\text { hopefulness and willingness to bring them back in pre-admission status. }\end{array}$ & 3.30 & Strongly agree & 3.50 & Strongly agree \\
\hline \multicolumn{5}{|c|}{ 4. Availability of support, such as venting out of struggling feelings, after the death experience is given by the following: } \\
\hline a. Peers & 3.20 & Agree & 2.97 & Agree \\
\hline b. Family & 3.40 & Strongly agree & 3.37 & Strongly agree \\
\hline c. Institution, including co-workers & 3.40 & Strongly agree & 3.03 & Agree \\
\hline 5. Constant exposure to death cases makes me feel conscious of my own mortality. & 3.20 & Agree & 2.8 & Agree \\
\hline 6. I utilized my knowledge in death experiences to enhance my nursing care. & 3.60 & Strongly agree & 3.17 & Agree \\
\hline $\begin{array}{l}\text { 7. I learn from the death experiences, which increases my effectiveness and leads to the } \\
\text { development of my skills of lifelong knowledge. }\end{array}$ & 3.50 & Strongly agree & 3.30 & Strongly agree \\
\hline $\begin{array}{l}\text { 8. I believe that stress debriefing plays an important role in the coping processes of nurses, } \\
\text { in losing patient. }\end{array}$ & 3.30 & Strongly agree & 3.37 & Strongly agree \\
\hline $\begin{array}{l}\text { 9. I need to cope up effectively and efficiently with death utilizing some psychological } \\
\text { concepts, such as with Kubler-Ross Five Stages of Grief Model. }\end{array}$ & 3.40 & Strongly agree & 3.30 & Strongly agree \\
\hline $\begin{array}{l}\text { 10. I believe that acceptance plays an important factor in order to cope with death/ losing } \\
\text { patients. }\end{array}$ & 3.70 & Strongly agree & 3.43 & Strongly agree \\
\hline Average Weighted Mean & 3.39 & Strongly agree & 3.25 & Agree \\
\hline
\end{tabular}

WM, weighted mean; $D$, description

The average weighted mean for Hospital A is 3.39 with verbal interpretation of strongly agree. This implies that the respondents deliver their nursing care to the dying patients with utmost professionalism and believe that acceptance plays a vital role in the coping process. Professionalism in nursing is an essential element in achieving a healthy work environment and is enabled by the context of practice. In addition, James et al. ${ }^{4}$ stated that in order to maintain professionalism, nurses must understand and accept their own feelings and beliefs about death. Meanwhile, accepting the inevitability of death requires a fairly radical transformation of self. One way to accomplish this is to loosen the connections between the self and the aspects of life.

For Hospital B, item no. 3 which states that, "I am still grateful for the services rendered towards peaceful death of patient besides my hopefulness and willingness to bring them back in pre-admission status" got the highest weighted mean of 3.50 with verbal interpretation of strongly agree. Followed by item no. 1 which states that, "I render end-of-life care which involves supporting the general well-being of patients" with the weighted mean of 3.47 with verbal interpretation of strongly agree. While item no. 5 which states that, "Constant exposure to death cases makes me feel conscious of my own mortality" got the lowest weighted mean of 2.80 with verbal interpretation of agree.

The average weighted mean for Hospital B is 3.25 with verbal interpretation of agree. This implies that the respondents are still grateful for their nursing services rendered to the dying patients towards peaceful death. Being thankful and grateful for the care and relationships, nurses help all the concerned individuals to adapt to condition and still maintain a positive outlook.

Table 6 illustrates the result of t-test to determine the significant difference of the assessed coping in losing patience of two-respondent hospitals. There is a mathematical difference among the mean assessed copings of staff nurses in losing patients. Results indicate that the computed t stat value (1.74287) is less than the t critical value of 1.79588 set at 0.05 level of significance. There is enough evidence found to accept the hypothesis of the study. Therefore, there is no significant difference between the assessed coping experiences of staff nurses from two-respondent hospitals. 
Table 6 Result of t-test to determine the significant difference of the assessed coping in losing patience of two-respondent hospitals

\begin{tabular}{|c|c|c|}
\hline \multicolumn{3}{|c|}{ t-Test: Paired two sample for means } \\
\hline & Hospital A & Hospital B \\
\hline Mean & 3.39167 & 3.25333 \\
\hline Variance & 0.04447 & 0.04719 \\
\hline Observations & 12 & 12 \\
\hline Pearson correlation & 0.1753 & \\
\hline Hypothesized mean difference & 0 & \\
\hline df & 11 & \\
\hline t Stat & I.74287 & \\
\hline $\mathrm{P}(\mathrm{T}<=\mathrm{t})$ one-tail & 0.0546 & \\
\hline t Critical one-tail & 1.79588 & \\
\hline $\mathrm{P}(\mathrm{T}<=\mathrm{t})$ two-tail & 0.1092 & \\
\hline t Critical two-tail & 2.20099 & \\
\hline
\end{tabular}

$*_{t}$ value is significant at 0.05

\section{Conclusion}

From the findings of the study, the following conclusions were drawn

I. Majority of the staff nurses, in both respondent hospitals, were observed to be high in their coping in losing patients.

II. For Hospital A, delivering their nursing care to the dying patients with utmost professionalism and believing that acceptance plays a vital role in the coping process commonly contributed in their coping experiences in losing patients
III. For Hospital B, it is still grateful that their rendered nursing services adds to the quality of life towards the peaceful death of the dying patients.

IV. Findings have valuations to nursing practice, education and research. The implication of the study to the nursing practice is to enhanced the coping skills of nurses in losing patients such as providing essential updates in dealing with dying patients, support from fellows that forms immense camaraderie, and psychosocial team building activities.

The implication of this study to the nursing education and research is to give strengthen the concept of caring for the dying and nurse's coping in losing patients that will be of practical use in such profession. The researcher understands that this study will contribute in broadening the perspectives of Filipino nurses on coping interventions in losing patience and encourage other researchers for further research and integrate them to nursing practice and education.

\section{Acknowledgments}

None

\section{Conflicts of interest}

The author declares no conflict of interest.

\section{References}

1. Villanueva JC. Biag Ikararuwa: coping experiences of filipino nurses in losing patients. Dr. Gloria D. Lacson Foundation College, Inc. 2017.

2. Finkelman A. Kenner C. Professional nursing concepts: competencies for quality leadership. 3rd ed. USA: Jones \& Bartlett Learning; 2016:610.

3. Atkins R. Getting the most from nursing school: a guide to becoming a nurse. USA: Jones \& Bartlett Learning; 2009:256.

4. James SR, Nelson K, Ashwill J. Nursing care for children: principles and practice. 4 th ed. St. Louis, Missouri, USA: Elsevier Saunders; 2013:262. 